\title{
EL DESTINO DE LA NOBLEZA NOVOHISPANA EN EL SIGLO XIX: ¿DECADENCIA O ADAPTACIÓN?
}

Verónica Zárate Toscano

Instituto de Investigaciones Dr. José María Luis Mora

¿QUÉ ERA UN NOBLE?

T a clásica obra de William Shakespeare Romeo y Julieta Lrecoge una preocupación nominativa que bien podríamos aplicar a los nobles novohispanos. En el balcón, Julieta se pregunta "What's in a name? That which we call a rose, by any other name would smell as sweet". ${ }^{1}$ ¿Podríamos entonces pensar que un noble, con otro nombre, sería igual de distinguido?

La nobleza novohispana a fines del siglo XviII tenía características particulares, aunque compartía rasgos con la nobleza española de viejo cuño. A fines de la época colonial, un elevado número de títulos nobiliarios se otorgó a personajes

Fecha de recepción: 16 de enero de 2015

Fecha de aceptación: 21 de julio de 2015

${ }^{1}$ Shakespeare, Romeo y Julieta, p. 26, “¿qué puede haber dentro de un nombre? Si otro título damos a la rosa con otro nombre nos dará su aroma”. 
que bien podrían considerarse integrantes de la ascendente burguesía. La mayoría de estos titulados emprendedores, gracias a su esfuerzo e ingenio, habían obtenido éxito económico y junto con él un lugar destacado en la sociedad. Apoyaban la legitimación del grupo social en el hecho nobiliario basado en la sangre, la raza, el orden absolutista, el linaje, la apariencia, pero también, cada vez más se tomaron en cuenta los valores de la virtud, la razón, el mérito y los derechos naturales. En resumen, los donativos otorgados a la corona, la inversión para hacer florecer la economía de una región por medio de la minería, el comercio, la agricultura, el valor en acciones de guerra, consolidaron a la nobleza en Nueva España a finales de la era borbónica.

De todos los títulos otorgados durante la época colonial, muchos se habían suprimido y otros se habían concentrado en unas pocas familias. Así pues, al momento de consumarse la independencia de México respecto a España, sólo quedaban vivos representantes de la cuarta parte de todos los títulos otorgados. En ese momento seguían vigentes alrededor de 31 distinciones. La investigación que he realizado en torno a los nobles, ${ }^{2}$ y que retomo aquí, se cierra al momento en que fueron falleciendo aquellos que alguna vez disfrutaron de la distinción de nobleza, lo que explica por qué su número va disminuyendo paulatinamente.

Entre los nobles analizados también habría que distinguir a los que apenas eran la primera generación en empezar a gozar del título al momento de la independencia, frente a las familias que llevaban cinco, seis, siete y hasta once generaciones con el blasón. Algunos tenían añejas tradiciones

2 Zárate Toscano, Los nobles ante la muerte. 
mientras que otros apenas empezaban a conformarlas con el tinte "nobiliario". Las familias con títulos más antiguos, al tener ya varias generaciones en tierras americanas, podrían compartir más características con los criollos de otros estratos. Si bien es cierto que parte de las estrategias matrimoniales podrían estar encaminadas a mantener nexos con la Península y renovar a las familias con sangre peninsular, sus vínculos con el nuevo mundo eran mayores que con el viejo. En cambio, los beneficiados con títulos de más reciente creación solían ser peninsulares que habían logrado fortuna y distinción en Nueva España y, al tiempo que destacaban y mantenían sus peculiaridades de españoles de viejo cuño, buscaban insertarse en la élite novohispana.

Las diferencias entre los nobles también se hacían evidentes por las regiones de su procedencia en la vieja o la Nueva España, e incluso según si eran hombres o mujeres quienes poseían el título. Pierre Serna afirma que, "aunque existe un estilo de vida nobiliario unificador y reconocido, los itinerarios biográficos son ampliamente heterogéneos [...] El noble es comprensible en una interacción constante entre sus modos de sociabilidad, codificados e integrados en un sistema de valores e ideas que aplica, adopta o utiliza". ${ }^{3}$

Un rasgo distintivo de estos nobles era su permanente necesidad de demostrar su estatus por diferentes medios, lo que los reafirmaba frente a una sociedad con marcadas desigualdades. Gozaron de privilegios y prerrogativas, colocaron sus blasones en las fachadas de sus elegantes mansiones, ejercieron ciertas funciones reservadas para ellos, ocuparon lugares preeminentes en actos religiosos, sociales y políticos,

${ }^{3}$ Serna, "El noble", p. 68. 
portaron distinguidas vestimentas, fueron objeto de majestuosos funerales, etc. Su participación en rituales les confería una visibilidad que los hacía un modelo a imitar, a la vez que era una clara muestra de su jerarquía. Tenían que demostrar que eran dignos de la estima social, no sólo con ese lucimiento sino con la derrama de sus bienes en la tierra para asegurar un lugar en el cielo, de ahí que invirtieran en obras materiales que fueran testimonio de su riqueza pero también de su piedad.

Podemos hablar de un desdoblamiento de actitudes entre los nobles. Frente a la sociedad tenían que mostrarse como ese modelo digno de imitación, pero era dentro de la familia donde se desarrollaban, inculcaban y conservaban valores, tradiciones, actitudes y comportamientos que les permitieran estima social, posición, rango, honor, prestigio, formas de conexión con los congéneres, símbolos y mitos sociales, etiqueta, estilo de vida, educación, formas de entretenimiento, antecedentes familiares, sensibilidad moral, mentalidad, creencias, $y$, en fin, el lugar y el papel que se juega en la vida para formar parte del grupo social más admirado y anhelado. ${ }^{4}$ Cuando podían mostrar al mundo los títulos nobiliarios, lo hacían. Cuando había un impedimento legal para ostentar, es decir, durante la república, se replegaban dentro de la familia y del grupo, manteniendo estrechos vínculos entre sí.

Lo que nos interesa en esta ocasión es responder a las siguientes preguntas: ¿Cómo fue la vida de los nobles en el siglo XIX mexicano una vez que se suprimieron las distinciones? ¿Qué tanto afectó el cambio de estatus jurídico a

${ }^{4}$ Mousnier, Social Hierarchies, p. 16. 
los integrantes de la nobleza, despojados de sus títulos, para mantenerse en un lugar privilegiado de la sociedad? ¿Cuáles fueron los móviles de adaptación a una nueva realidad y un nuevo régimen, y de qué mecanismos se valieron para insertarse en la naciente república o en los intentos monárquicos? ¿Se podría hablar de una doble vida, es decir, se cumplía la norma de usar los apellidos en vez de los títulos, pero en la intimidad familiar se mantenían prácticas y estrategias de consolidación del grupo, de solidaridad? ¿Los nuevos retos de la situación económica, con la supresión de mayorazgos, abrieron la puerta a los exnobles para incorporarse a otras profesiones?

\section{SUPRESIÓN DE LOS TÍTULOS}

En un régimen monárquico, la nobleza tenía un sentido, de ahí que "marqués" fuera gobernador de frontera y "conde" fuera compañero del rey en la guerra, ${ }^{5}$ pero ese sentido original se perdió con el paso del tiempo. Cuando México se convirtió en un país independiente e ingresó a un breve episodio imperial, se aprovechó al selecto grupo de los nobles para conformar la corte de Agustín I, es decir, que una de sus funciones fue arropar al emperador. Pero cuando el efímero imperio terminó y entró en vigor el sistema republicano, la nobleza dejó de tener sentido y vigencia, al menos en términos legislativos, aunque en las prácticas sociales que compartían sus integrantes, continuaron a lo largo de varias décadas.

${ }^{5}$ González-Doria, Diccionario heráldico y nobiliario, p. 50. 
En las cámaras de diputados y senadores se debatió sobre la pertinencia de suprimir los títulos y los mayorazgos. El 2 de mayo de 1826 se firmó una ley que decía:

Quedan extinguidos para siempre los títulos de conde, marqués, caballero y todos los de igual naturaleza, cualquiera que sea su origen. El gobierno dispondrá se destruyan por los dueños de edificios, coches y otros muebles de uso público, los escudos de armas y demás signos que recuerden la antigua dependencia o enlace de esta América con España. ${ }^{6}$

Uno de los puntos más relevantes del decreto es la manifestación del deseo de cortar de tajo cualquier vestigio que quedara de los vínculos que anteriormente habían unido a España con su posesión más próspera.

Vale la pena analizar la discusión que generó esta iniciativa, para conocer las razones que llevaron a proponerla. La prensa del momento participó del debate y se hizo eco de algunas críticas, pero también incluyó expresiones positivas sobre la actitud que habían tomado algunos poseedores de títulos ante la nueva realidad. En el periódico Águila Mexicana se decía:

El acuerdo para supresión de títulos de Castilla ha enfurecido a algunos bichos que eran o esperaban ser condes o marqueses o barones; pero se debe decir, en honor de la generalidad de los mejicanos [sic] que gozaban esas distinciones, que todos ellos miraban con indiferencia tales títulos y aun habían

${ }^{6}$ Dublán y Lozano, Legislación mexicana, ley de 2 de mayo de 1826, n. 474, t. I, p. 777, http://www.biblioweb.tic.unam.mx/dublanylozano/ [Citado 20 abril 2014]. 
tenido el buen juicio de llamarse con anterioridad por sus propios nombres.

El prestigio que daba un título se había manifestado en que los agraciados habían cambiado su "nombre y apellido" por la denominación de la merced obtenida. Por ejemplo, Pedro Romero de Terreros se convirtió en el Conde de Regla. Este prestigio social subsistió a la ruptura del régimen colonial aunque con algunos matices, pues los reacios al cambio siguieron firmando con su distinción pero anteponiéndole el prefijo “ex”. Los demás regresaron, con honestidad y acaso con orgullo, a los antiguos apellidos.

Respecto a los mayorazgos, con el avance de la modernidad, también se dio un debate en torno a la necesidad de suprimirlos. La añeja costumbre de favorecer al primogénito con la mejor parte de la herencia, que implicaba la vinculación de bienes a fin de no poderlos vender pero sí usufructuar, empezó a convertirse en un obstáculo para la circulación de bienes e incluso para el sostenimiento de los titulados. No todos los nobles poseían o llegaban a fundar un mayorazgo ni todos los vínculos eran propiedad de nobles. Desde fines del siglo xvin se emitieron diversas disposiciones para limitarlos y las Cortes españolas los abolieron, tanto para España como para América, el 20 de septiembre de $1820,{ }^{8}$ disposición que fue recibida con cierto beneplácito entre muchos mayorazgos novohispanos. La discusión giró en torno al momento de aplicar tal

\footnotetext{
7 Águila Mejicana (jueves 11 mayo 1826).

8 En el Diario de las actas ... de 1820 y 1821, pueden verse las extensas discusiones en torno al tema durante el mes de septiembre, hasta que el 20 se aprueba la disposición.
} 
precepto una vez que México rompió sus lazos con España. ${ }^{9}$ Los mayorazgos se habían convertido en un lastre para las familias, ya que los bienes tenían que estar bajo la tutela de sólo uno de los descendientes y en consecuencia eran un obstáculo para el desarrollo individual, muy en boga por las teorías liberales. No olvidemos que los mayorazgos, como herencia, se habían utilizado como mecanismo para no dispersar los capitales. Al ceder el paso a la modernidad, suprimirlos y permitir la libre circulación de bienes, se dieron mayores posibilidades de éxito económico que no se hubieran logrado con las limitaciones que imponía la vinculación.

\section{MOVILIDAD GEOGRÁFICA}

Entre los que asistieron a la transformación de la colonia en el México independiente, hubo algunos que, ya en la víspera de la independencia o una vez consumada, salieron de México para no volver. El segundo Conde de la Cortina, Vicente Gómez de la Cortina, español de nacimiento, “creyó de su deber retirarse a su país, en donde, por sus virtudes, más bien que por su fausto, conservó el ilustre rango de sus mayores y fue agraciado por la corte de Madrid con varias distinciones". ${ }^{10}$ Su esposa, María Ana Gómez de la Cortina, quien era la poseedora del título, permaneció en México y lo

9 LAdD, La nobleza mexicana, pp. 230-238. Clavero, Mayorazgo, pp. 361-369. En el primer Congreso mexicano posterior al imperio de Iturbide se discutió la ley de mayorazgos que autorizó que pasara al sucesor el título con la mitad del mayorazgo, "en cuya virtud el gobierno estaba cobrando las lanzas que no es una contribución tan despreciable para un erario pobre”. El Sol, núm. 693 (7 mayo 1825).

10 Copca, Apuntes biográficos, p. 5. 
siguió ostentando, no siempre anteponiéndole el “ex”, como muchos otros. A su muerte, su hijo José María Justo Gómez de la Cortina, distinguido científico, solicitó en España la sucesión a dicha dignidad. Con el fin de usar en México el título de tercer Conde de la Cortina, obtuvo permiso de ambos gobiernos para renunciar a la nacionalidad mexicana y adoptar la española, ${ }^{11}$ y permaneció en el pináculo de la sociedad, de la política y de la cultura.

Por su parte Felipe Zabalza, Marqués Consorte de Selva Nevada IV, vendió todo lo que pudo y, una vez que se consumó la independencia, se embarcó con su familia de regreso a su tierra natal, la Rioja, pero falleció en el mar. Su esposa, doña Soledad, nacida en México, dejó a dos de sus hijas en España y una de ellas refrendó el título, mientras que la viuda, quien había gozado del marquesado en el nuevo mundo, no desaprovechó la oportunidad de regresar a su propia tierra. ${ }^{12}$ Así una distinguida familia noble se vio fracturada por acontecimientos políticos y sus integrantes continuaron su descendencia y su lustre a ambos lados de la mar océano. Aunque fue la rama española la que conservó la distinción del título nobiliario, la mexicana continuó, aunque no libre de dificultades, por un par de generaciones.

José Antonio Rengel, primer Conde de Alcaraz, mostró una verdadera obsesión, en la década de 1800, por volver a su natal Málaga y así lo manifestó en diversas ocasiones. En caso de no poder verificarlo él, deseaba que sus hijos se trasladaran a España para su mejor educación, sobre todo

11 Cortina, Poliantea, y Biografía. Para conocer su participación en las sociedades científicas y literarias véase MAYER CELIS, Entre el infierno. 12 Zárate Toscano, “Estrategias matrimoniales”, pp. 227-254. 
después de que Andalucía había quedado liberada de los franceses. ${ }^{13}$ La muerte le impidió realizar su propósito, pero sus dos hijos varones intentaron cumplir el deseo de su padre; sin embargo, fallecieron en el mar y en La Habana, respectivamente. Su hija, María Guadalupe Rengel y Fagoaga quien sería la tercera condesa, contrajo matrimonio con Bernardo del Castillo, quien fue nombrado diputado por Zacatecas en las Cortes de 1820 y se preparó para viajar a Europa. ${ }^{14}$ No se tiene la certeza de si murió en el mar o en España, pero el caso es que la condesa quedó viuda y contrajo segundas nupcias en México en 1824 con Felipe Neri del Barrio y Larrazábal, ministro plenipotenciario de Guatemala. El hecho de que dicha familia fuera distinguida con un título concedido por el rey de España no impidió que sus descendientes se enlazaran con funcionarios liberales.

Hubo otros nobles que abandonaron Nueva España y dieron su último soplo de vida en otras tierras. María Josefa López de Peralta Villamil, Condesa Consorte de Regla III, después de ser dama de honor de la emperatriz Ana María de Iturbide, se divorció de su marido y salió de México en 1826 rumbo a Europa, pero falleció en Nueva York. ${ }^{15}$

En condiciones distintas pero buscando también alejarse de la tierra natal, habría que mencionar a José María Antonino Romero de Terreros Trebuesto y Dávalos, Marqués de San Cristóbal, quien desde joven rechazó el oropel de la nobleza y trató de huir de la presión familiar. Tras distintas

13 AHNCM, Fernando Tamayo, núm. 673, 4 de marzo de 1813, testamento del Conde de Alcaraz I.

14 AHNCM, Eugenio Pozo, núm. 530, 13 de diciembre de 1820, testamento del Conde de Alcaraz III.

15 Romero de Terreros, Los Condes de Regla, pp. 93-96. 
muestras de rebeldía, avatares y aventuras, se instaló en París, donde estudió medicina y defendió su tesis en 1804. Después de realizar una serie de experimentos científicos con su propio cuerpo, ingiriendo quina, falleció a mediados de $1815 .{ }^{16}$

Finalmente, José Francisco Fagoaga y Villaurrutia, exMarqués del Apartado, segundo en el título, elaboró su testamento en 1838, “estando próximo a partir para Europa y temeroso de los riesgos que pueden amenazar mi existencia en este largo viaje”, y terminó sus días soltero en París en 1842. ${ }^{17}$

En algunos casos, esta movilidad geográfica podría ser fruto del sentimiento de los oriundos de la Península que anhelaban volver a ella con el lustre y el poder económico adquiridos en el nuevo mundo. Lejos del sistema republicano mexicano, renovaron sus títulos nobiliarios en la Península, algunos de los cuales siguen vigentes el día de hoy. ${ }^{18}$ Otros nobles deseaban que sus hijos no echaran raíces en América y pensaban que la educación que recibirían en Europa sería mejor. Estos rasgos no son exclusivamente decimonónicos ni nobiliarios, pero los resaltamos para demostrar que no por el hecho de ser distinguidos con un título dejaban de poseer una visión realista o pragmática compartida por sus coetáneos. Sin embargo, en otros casos son manifestación explícita de dejar atrás el pasado y buscar nuevas oportunidades en horizontes distintos.

16 Romero de Terreros, “El primer Marqués de San Cristóbal”, pp. 133136. Estamos esperando tener el tiempo suficiente para poder averiguar más sobre este personaje.

17 AHNCM, Manuel García Romero, núm. 286, 24 de enero de 1838, testamento del Marqués del Apartado II.

18 Elenco de grandezas. 
En cuanto a la movilidad social, los ejemplos comentados a continuación dan algunas pistas. En el México independiente, las transformaciones políticas, económicas y sociales operadas en las primeras décadas del siglo XIX provocaron algunos cambios en los antiguos nobles, quienes, para no desaparecer, conservaron firmemente tradiciones, comportamientos y valores inculcados dentro de sus familias durante varias generaciones. A medida que iba disminuyendo la presencia social de la nobleza, estas prácticas fueron interiorizándose y circunscribiéndose a ámbitos más estrechos. Cada vez más, la familia se convirtió en la organización social clave para conservar, transmitir y reproducir los valores y conductas fundamentales de la nobleza novohispana. Y sin embargo se empezaron a notar algunas innovaciones.

Cuando María de la Soledad Gutiérrez del Rivero y Rodríguez de Pinillos, cuarta Marquesa de Selva Nevada, regresó viuda a México, buscó la mejor manera para sacar adelante los negocios familiares y no dudó en asociarse con el inglés Tomás Gillow, quien no sólo le administró los bienes sino que contrajo nupcias con ella. ${ }^{19}$ Esta estrategia no era desconocida en la época colonial, cuando las familias seleccionaban, para las mujeres poseedoras de un título de nobleza, un marido en función de su habilidad administrativa. Pero en este caso, la excepción es que el contrayente no había nacido en el imperio español y aparentemente no tenía mayores atributos. El cerco impuesto por la corona española para impedir la intervención abierta de extranjeros en los

19 ZÁrate Toscano, “Estrategias matrimoniales”, pp. 227-254. 
asuntos internos del imperio no continuó siendo efectivo al momento en que México se independizó y buscó toda clase de apoyos para salir adelante. Las nupcias de la exmarquesa, independientemente de los sentimientos que estuvieran involucrados, nos hablan de una apertura y de los cambios sociales que permitían una movilidad que no puede calificarse fácilmente de ascendente o descendente. Ella no necesariamente se rebajó al casarse con un relojero emprendedor y él no necesariamente se elevó cuando tuvo que invertir sus bienes para sacarla a ella y a su familia adelante. Cabría preguntarse cómo un extranjero, que se ganaba la vida con su trabajo manual, de origen incierto, era un buen candidato. Aunque ella fuera viuda, conservaba valores que se estaban rasgando. El caso es que ambos lograron así mantener el lustre -y las posesiones- de una familia noble que había sufrido, como tantas otras, las consecuencias económicas de la independencia pero que seguía siendo de las más prominentes en los albores de la nueva nación. ${ }^{20}$

Las estrategias seguidas por las familias nobles estaban encaminadas a mantener su lustre y distinción, y por ello no podía permitirse que los hijos rompieran las reglas y contrajeran nupcias con personas de calidad dudosa. Así, los padres patriarcas buscaban impedir matrimonios desiguales en la época colonial. La segunda Marquesa de San Clemente, María Ana de Pereda, amenazó a su hijo con desheredarlo si

20 Otra familia que aceptó inversión extranjera para sacar adelante sus empresas fue la de los Condes de Regla. Les rentaban las minas a los ingleses, lo que constituía un gran negocio para los mexicanos y un gran fracaso para los británicos. Randall, Real del Monte. Una vez más, se mantenía una vieja costumbre colonial en la que el propietario de bienes arriesgaba poco y vivía de las rentas. 
se casaba con una mulata en $1785 .{ }^{21}$ Pero a finales de la época colonial, pareció haber mayor flexibilidad social, cuando Andrés Diego Hurtado de Mendoza, octavo Conde del Valle de Orizaba, pudo casarse en 1802 con una mujer que, según el parecer de su padre, era una persona impura que lograría que se "obscureciese [el] esplendor" de la familia. ${ }^{22}$ Recordemos que, desde 1776, la Pragmática de Matrimonios había establecido reglas muy claras en cuanto a las calidades de los consortes y las desigualdades entre ellos. ${ }^{23} \mathrm{Ni}$ siquiera entre los nobles se pretendió observarla y posteriormente perdió todo valor legal. En el México independiente no hubo una observancia tan estricta de tales disposiciones, que serían impensables en el marco de una república democrática pero que en la realidad seguían existiendo.

Una opción para detener tales arrebatos de rebeldía era la amenaza de desheredación, que podría no llevarse a la realidad, al menos en casos vinculados con los afectos de fines de la época colonial. A mediados del siglo xix, los motivos para privar a un hijo de la herencia se seguían relacionando con cuestiones de honor. José María Gómez de Cervantes y Altamirano, décimo Marqués de las Salinas del Río Pisuerga, y su hijo mayor, José Juan Cervantes y Michaus, habían entablado un pleito cuando el hijo, que aún era menor de

21 AHML, c. 1785-86, oposición de María Ana de Pereda, segunda Marquesa de San Clemente, al matrimonio de su hijo Pedro de Busto con Andrea Martínez por desigualdad de sangre.

${ }^{22}$ AGI, MP. 16, Escudos, 278, Árbol genealógico de Andrés Diego Suárez de Peredo. Aguirre Beltrán, Cuatro nobles, pp. 21-65.

23 "Pragmática Sanción para evitar el abuso de contraer matrimonios desiguales", 23 de marzo de 1776, en Konetzke, Colección de Documentos, vol. III, primer tomo, pp. 406-412. 
edad, solicitó la habilitación para administrar sus bienes. Por la muerte de su madre y su abuelo materno, se había declarado huérfano, lo que representaba una seria afrenta para su padre. En su testamento de 1842, alegando que las acciones de su hijo afectaban sus negocios y que le faltaba "al respeto y consideraciones que como a su padre y señor debiera tributarme, resultando de tales procedimientos mi inmerecida difamación y el escándalo de nuestra enemistad”, ${ }^{24}$ el marqués decidió desheredarlo. El estigma social resultaba muy perjudicial, tanto para él como para su linaje. Cuando las aguas volvieron a su cauce y el hijo recapacitó, el conflicto se resolvió.

Pero así como se dieron casos de familias reconstituidas, también hubo rupturas significativas. María Josefa López de Peralta Villamil, Condesa Consorte de Regla III, hija de la famosa Güera Rodríguez, se divorció en 1826. Si bien existieron otros casos de divorcio entre los integrantes de la nobleza novohispana,${ }^{25}$ ninguno de ellos fue tan escandaloso como éste, en que ella dejó atrás a sus hijos, cuyas edades iban de los 2 a los 11 años, y puso tierra de por medio ante una situación familiar insoportable, haciendo uso de las nuevas ideas liberales. Muchas mujeres hubieran querido hacer esto pero se habían detenido por las reglas sociales que se les habían impuesto. Aunque su destino era Europa, en el camino enfermó y falleció en Nueva York, siendo sepultada en la iglesia de San Patricio, en la Quinta Avenida. En México se

24 AHNCM, Manuel García Romero, n. 286, 27 de abril de 1842, testamento del Marqués de las Salinas X.

25 Otros nobles que pasaron por procesos de divorcio fueron los Marqueses de Jaral y Moncada en 1792; los Condes de San Pedro del Álamo en 1816 y los Condes de Pérez Gálvez en 1818. 
llevaron a cabo unas pomposas honras fúnebres en el Oratorio de San Felipe Neri, a las que concurrió la crema y nata de la sociedad, parientes y amigos de la casa de Regla. ${ }^{26}$ Podríamos preguntarnos qué se diría de la difunta en tales circunstancias, pero también podríamos pensar que los asistentes se hacían presentes para solidarizarse con el distinguido don Pedro Romero de Terreros o con los hijos que quedaban en la orfandad. En tiempos difíciles, las familias distinguidas cerraban filas y permitían la participación de los integrantes del selecto grupo para arropar a sus integrantes.

Otra llamativa ceremonia fúnebre que involucró a algún integrante de la antigua nobleza novohispana se efectuó en abril de 1842. La familia de Loreto Gómez de la Cortina, hija de los segundos Condes de la Cortina y hermana de José Justo, el tercer conde, no dejó pasar la oportunidad de mostrar los galones de su otrora grandeza y realizó una pomposa ceremonia en el templo de San Francisco. Para mayor lucimiento, algunos miembros de la Compañía de Ópera italiana, que a la sazón estaba en la ciudad de México, encabezados por la contralto Adela Cesari, interpretaron las piezas musicales que exigía el rito, acompañados del coro franciscano. ${ }^{27}$ La ceremonia duró desde las nueve hasta las doce del día, hora en que se le dio sepultura en la capilla de Burgos. La descripción de un invitado a las honras terminaba con un comentario por demás elocuente: "la concurrencia de hombres y mujeres fue numerosa. Parecía

\footnotetext{
${ }^{26}$ Romero de Terreros, Los Condes de Regla, pp. 93-96.

27 Bourdieu, La distinción, p. 16, afirma que no hay nada más enclasante que la música. Por ello es revelador que hayan logrado hacer participar a los integrantes de la compañía en un ritual tan significativo, mostrando su gusto por la música clásica y elitista.
} 
Jueves Santo, según la gente y el lujo". ${ }^{28}$ Evidentemente donde podría mantenerse el boato y lucirlo públicamente era en el postrer homenaje de una distinguida dama que había contraído nupcias con José María Gutiérrez Estrada, monarquista recalcitrante, involucrado posteriormente en la instalación del Segundo Imperio. Los intereses monárquicos de los Cortina contrastan con las tendencias republicanas de los Regla. Unos se adaptaron, otros renegaron, pero paralelamente surgieron otros personajes que se fueron colocando en el selecto círculo de la distinción decimonónica.

Como podemos constatar, los exnobles sí conservaron sus rituales, con los que lograban la unidad en lo heterogéneo y en los que volvían a manifestar unidad y pertenencia al grupo de una categoría mayor y de la que pocos podían participar. Pero también tuvieron que dar cabida a los nuevos personajes prominentes que poco a poco fueron asimilando sus costumbres y manifestaciones de distinción. ${ }^{29}$

\section{CONCLUSIONES}

Hay una característica que es esencial del noble y es que ha sido necesario a lo largo de la historia. Desde sus remotos orígenes, ha sido el modelo a seguir, el ideal, el ejemplo. Ha sido capaz de usar la espada para defender la patria, el honor, la monarquía, y ése es el compromiso implícito del noble con el pueblo. El noble recibe las rentas, los servicios de la gente, pero al mismo tiempo tiene una responsabilidad hacia los que están cerca de él y bajo su dependencia. Los

28 Romero de Terreros, Cosas que fueron, pp. 189-195.

29 Bourdieu, La Noblesse d'État. 
novohispanos también sintieron ese compromiso de hacer algo por el pueblo, para que su existencia tuviera sentido y no fueran vistos como inútiles. Los que se quedaron una vez consumada la independencia siguieron sintiendo ese compromiso, aunque desapareciera su título, para sacar adelante a su patria.

En el naciente país, la mayoría de los nobles que sobrevivieron como tales ocuparon puestos administrativos, se dedicaron a las profesiones liberales y organizaron nuevas empresas. Socialmente, su grupo familiar continuó creciendo y mantuvieron patrones de matrimonio similares a los que estaban vigentes durante la época virreinal, pero incorporando ahora a miembros de los nuevos grupos en el poder. Algunos llegaron a formar parte de asociaciones científicas, como la Sociedad Mexicana de Geografía y Estadística; tal es el caso del segundo Conde de Bassoco, José María Bassoco de los Heros. Y no podemos pasar por alto que algunos más se distinguieron en altos puestos del ejército, como José Morán y del Villar, marido de María Loreto de Vivanco, tercera Marquesa de Vivanco, quien llegó a ser jefe del estado mayor del ejército.

Cabría preguntarse si se adaptaron a la realidad política al ocupar nuevos cargos o siguieron aprovechando sus viejas prerrogativas en nuevas instancias al convertirse en congresistas, gobernadores, ministros, y ocupar altos grados militares. Algunos podrían ser bastante liberales, aunque fueran nobles de pura cepa, tanto así que el mero hecho de dedicarse a la política fue porque estaban convencidos de que les tocaba gobernar por estar hasta arriba de la pirámide social. Podríamos considerar que reclamaban su prestigio 
ocupando los lugares que les correspondían y dirigiendo a un país al que algunos tenían muy claro hacia dónde llevarlo.

Cuando se dio el enfrentamiento entre realistas e insurgentes en la guerra de independencia, podríamos pensar que los nobles, por tener un título sancionado por la monarquía española, lucharían del lado de los realistas, pero no es así. Algunos perdieron la vida, efectivamente, defendiendo los intereses del rey de España, como el Conde de Casa Rul, coronel graduado del ejército, fallecido en el sitio de Cuautla. Este "patriotismo" se reflejó también en el comando personal de tropas y en las contribuciones y donativos para su manutención. ${ }^{30}$ Hubo otros integrantes de las familias nobles que se incorporaron a las filas insurgentes, como Antonio de Sesma, descendiente de los Marqueses de Sierra Nevada.

Algunos nobles defendieron a la patria "criolla" e incluso llegaron a firmar el acta de Independencia, como los Condes de Regla y de la Casa Heras Soto, y los Marqueses de San Miguel de Aguayo, de San Juan de Rayas, Salinas y Salvatierra. Cabe destacar que dos de ellos, más que plasmar su firma como titulados, lo hicieron con sus nombres y apellidos. Esta actitud puede llevar implícito un cambio en la mentalidad, en el significado de la nobleza como una manera de ser y de sentir, actitud que involucraba un sistema de representaciones distinto a partir de entonces.

Aquellos que habían disfrutado en vida algún título nobiliario fueron muriendo en el México independiente, pero en sus familias quedó el honor y la distinción que sacaron a relucir cuando la ocasión lo ameritaba, particularmente

30 En las gacetas de la época se publicaban largas listas con los nombres de los donadores y el monto que aportaban; entre ellos se encuentran muchos nobles. 
en el Segundo Imperio. Así pues, algunos descendientes de familias nobles rescataron sus viejos títulos y arroparon a Maximiliano de Habsburgo en la nueva corte imperial y en sus actos protocolarios. ${ }^{31}$ Fue una oportunidad dorada para mostrar sus dones y galones, aunque resultó un lustre efímero. Así, unos se adaptaron, otros renegaron de las apariciones de regímenes imperiales, pero el tiempo siguió corriendo y hubo que volver a prácticas más bien interiorizadas. Igualmente fue necesario trazar nuevas alianzas para mantener el boato y, al mismo tiempo, permitir el ingreso de nuevos integrantes a lo que había sido un selecto y reducido grupo.

Sería demasiado simplista suponer que todos los nobles eran conservadores en oposición a los republicanos liberales. No existían actitudes ni comportamientos puros ni eternos, sino que podrían ser cambiantes en función de las circunstancias. Manuel Romero de Terreros, descendiente de los Condes de Regla, no pudo resistir la implantación del Segundo Imperio en México y prefirió abandonar el país, dejando las fachadas de su casa pintadas de negro en señal de luto por el sistema impuesto. ${ }^{32}$

No podemos pasar por alto que estos personajes dejaron una cultura, unas actitudes, un estilo distinguido que recuperaron y asimilaron los que quedaron en la cúspide de la pirámide y con los que convivieron. Los antiguos nobles novohispanos aparecían, en el siglo xIX, en los actos públicos, tanto en ceremonias cívicas como religiosas, y en los espectáculos, como la ópera y el teatro. Eran a la vez impulsores y consumidores de música y artes escénicas. No faltaban en aquellas fiestas que tanto llamaban la atención de

31 Algara, La corte de Maximiliano.

32 PANI, “El proyecto”, p. 450. 
los viajeros, donde se hacía evidente el abismo social. Estaban presentes en la política, ocupando puestos que seguían controlando ciertas regiones. En ellos se advierte una capacidad para sobrevivir a los cambios, adaptando y guardando para mejores años sus creencias, valores y distinción. Y cuando llegaba la oportunidad, como en las cortes imperiales de Agustín de Iturbide y de Maximiliano de Habsburgo, sacaban a relucir su alcurnia y destellaban sus distinciones.

No es fácil conocer la vida cotidiana de estos personajes y familias que alguna vez ostentaron un título nobiliario y que permanecieron en el México independiente. Algunos viajeros como, Madame Calderón de la Barca, nos brindan algunas pinceladas de su cotidianidad, ${ }^{33}$ pero por lo general les podemos seguir el rastro en sucesos extraordinarios, en ceremonias, etc. Podemos conocer sus trayectorias cuando forman parte de la vida política, en sus transacciones económicas, en sus producciones culturales. Sería necesaria una investigación más detallada para abarcar estos y otros aspectos que por ahora apenas hemos vislumbrado.

Los móviles que los llevaron a adaptarse al cambio podrían ser distintos en cada caso, pero en términos generales hay que mencionar su deseo de permanecer en México, independientemente del régimen político que imperara, sobre todo en aquellas generaciones que ya habían visto la luz en el nuevo mundo. Ocultos o a la vista, participando o no de la política o de la bonanza económica, se mantuvieron en el pináculo de la sociedad como el modelo a imitar por parte de los que anhelaban pertenecer a la élite y a los que poco a poco tuvieron que abrir las puertas.

33 Calderón de la Barca, La vida en México. 
Es bien sabido que la modernidad se opone a las formas tradicionales de convivencia. Las nuevas sociedades siguieron inscritas en la tensión entre tradición y modernidad. Así, los nobles del xix fueron entrando en esta modernidad o en el sueño de la modernidad donde la burguesía se desenvuelve. Si bien es cierto que cuando se vislumbraba -o se había efectuado ya- el cambio de virreinato a república, muchos nobles prefirieron perder la nacionalidad que el título; también tendríamos que destacar a aquellos que eligieron permanecer en México. La nobleza, mayoritariamente conservadora y apegada a sus privilegios, se modernizó y se adaptó, cuando así convenía, al republicanismo, y buscó participar en la política y dirigir los destinos del naciente país.

Aunque no correspondan a nuestro espacio geográfico, no podemos evitar cerrar con las siguientes reflexiones. Si alguien podría considerarse "noble" sería la Duquesa de Alba, fallecida en noviembre de $2014,18^{a}$ persona en ostentar el título otorgado en 1472 y en quien recayeron 45 distinciones nobiliarias de todos los niveles, fruto de las uniones de sus ancestros durante siglos a lo largo y ancho de Europa. En su misa fúnebre, el arzobispo de Sevilla la definió como: "Noble de herencia, pero noble, muy noble, de corazón. Noble en la generosidad y en el servicio a los más necesitados”. Éste es el concepto de noble que parece privar en la España del siglo xxi. Por si fuera poco, el clamor popular decía que, “entre todos sus títulos, el mejor era ser sevillana". Y para rematar, ella misma redactó su epitafio: "Aquí yace Cayetana, que vivió como sintió". ${ }^{34}$ Podríamos entonces pensar en ella

34 "La hora del adiós a Cayetana” y Juan Ignacio Zoido, "Su mejor título es ser sevillana”, en El Mundo (21 nov. 2014), http://www.elmundo. 
como el mejor modelo de movilidad y convivencia, de adaptación y distinción, de linaje y a la vez de sencillez, de conciencia de su especificidad y también de su función en la sociedad. Las ceremonias fúnebres de que fue objeto fueron una demostración más de la pervivencia de viejas costumbres y de la adaptación a la modernidad. Unieron a su familia con la realeza, la nobleza, el funcionariado, lo más granado de la sociedad y a cientos de personas del pueblo llano que se arremolinaron para despedirla. Fue una noble que supo convivir con los integrantes de todos los estratos y logró así trascender más allá de los títulos o el "color" de su sangre.

Y finalmente cabe resaltar la reunión que sostuvo el rey de España, Felipe VI, con los representantes de la Diputación de la Grandeza de España a mediados de junio de 2015. En su discurso resaltó la necesidad de que los nobles mantengan su "compromiso solidario con el conjunto de la sociedad”. Agregó que "En la España constitucional sabéis bien que vuestros nombres no comportan más que un gran honor; honor que implica responsabilidad y conlleva unas obligaciones para con vuestros antepasados, con vosotros mismos, vuestras familias y con España”. ${ }^{35}$ Con esta afirmación podríamos contestar a la pregunta inicial de ¿qué es un noble en pleno siglo xxI?

es/loc/2014/11/21/546f133eca47410a228b4577.html. «Aquí yace Cayetana, que vivió como sintió», el epitafio que eligió la duquesa de Alba, abc.es/agenciasabc_es, 20 de noviembre de 2014, Madrid http://www.abc. es/estilo/gente/20141120/abci-epitafio-duquesa-alba-201411201210.html 35 "El Rey recuerda a los nobles de España su deber de observar una conducta ejemplar", La Vanguardia (16 jun. 2015), http://www.lavanguardia.com/politica/20150616/54432857443/rey-recuerda-nobles-espana-deber-observar-conducta-ejemplar.html 


\section{SIGLAS Y REFERENCIAS}

AGI Archivo General de Indias, Sevilla, España.

AHML Archivo Histórico Municipal de León, España.

AHNCM Archivo Histórico de Notarías de la Ciudad de México, México.

Aguirre Beltrán, Gonzalo

Cuatro nobles titulados en contienda por la tierra, México, Centro de Investigaciones y Estudios Superiores en Antropología Social, 1995.

Algara y Gómez de la Casa, Ignacio

La corte de Maximiliano. Cartas de don Ignacio Algara, que publica por primera vez con advertencia y notas don Manuel Romero de Terreros, México, Cultura, 1938.

Biografía

Biografía del Exmo. Sr. d. José M. Justo Gómez de la Cortina, Conde de la Cortina, escrita por una comisión de la Sociedad Mexicana de Geografía y Estadística, México, Imp. de A. Boix, 1860.

Bourdieu, Pierre

La distinción. Criterio y bases sociales del gusto, México, Taurus, 2002.

La Noblesse d'État. Grandes écoles et esprit de corps, París, Les éditions de Minnuit, 1989.

Calderón de la Barca, Fanny

La vida en México, México, Editora Nacional, 1957, 2 tomos.

Clavero, Bartolomé

Mayorazgo. Propiedad feudal en Castilla, 1369-1836, Madrid, Siglo Veintiuno editores, 1989. 
Copca, Bernardo

Apuntes biográficos de la señora doña María Ana Gómez de la Cortina, Condesa de la Cortina, México, Imprenta de Guillermo Veraza, 1885.

Cortina, Conde de la

Poliantea, selección y prólogo de Manuel Romero de Terreros, México, Universidad Nacional Autónoma de México, 1944.

Diario

Diario de las actas y discusiones de las cortes. Legislatura de los años de 1820 y 1821, Madrid, Imprenta Especial de las Cortes, 1820 , t. V.

Dublán, Manuel y José María Lozano

Legislación mexicana o colección completa de las disposiciones legislativas expedidas desde la independencia de la República. http://www.biblioweb.tic.unam.mx/dublanylozano/ [Citado 20 abril 2014], ley de 2 de mayo de 1826, núm. 474, t. I, p. 777.

Elenco

Elenco de grandezas y títulos nobiliarios españoles, Madrid, Hidalguía, 2015.

Gonzalbo Aizpuru, Pilar y Cecilia Rabell Romero (coords.)

Familia y vida privada en la historia de Iberoamérica. Seminario de Historia de la Familia, México, El Colegio de México, Universidad Nacional Autónoma de México, 1996.

GonzÁlez-Doria, Fernando

Diccionario beráldico y nobiliario de los reinos de España, Madrid, Bitácora, 1987.

Konetzke, Richard

Colección de documentos para la bistoria de la formación social hispanoamericana, 1493-1810, vol. III, primer tomo, Madrid, Consejo Superior de Investigaciones Científicas, 1962. 
LADD, Doris

La nobleza mexicana en la época de la independencia, 17801826, México, Fondo de Cultura Económica, 1984.

Mayer Celis, Leticia

Entre el infiero de una realidad y el cielo de un imaginario. Estadistica y comunidad científica en el México de la primera mitad del siglo XIX, México, El Colegio de México, 1999.

Mousnier, Roland

Social Hierarchies. 1450 to the Present, Nueva York, Schocken Books, 1973.

PANi, Erika

"El proyecto de Estado de Maximiliano a través de la vida cortesana y del ceremonial público", en Historia Mexicana, XvL:2 (178) (oct.-dic. 1995), pp. 423-460.

RANDALL, Robert W.

Real del Monte: una empresa minera británica en México, México, Fondo de Cultura Económica, 1986.

Romero de Terreros, Manuel

"El primer Marqués de San Cristóbal", en Siluetas de antaño, México, Ediciones Botas, 1937.

Cosas que fueron, México, Imprenta de J. I. Muñoz, 1937. Los Condes de Regla. Apuntes biográficos, México, Imprenta y fotografía de M. León Sánchez, 1909.

SERna, Pierre

“El noble”, en Vovelle, 1992, pp. 41-91.

SHAKESPEARE, William

Romeo y Julieta, traducción de Pablo Neruda, Santiago de Chile, Pehuén Editores, 2001. 
Vovelle, Michel y otros

El hombre de la Ilustración, Madrid, Alianza Editorial, 1992.

Zárate Toscano, Verónica

"Estrategias matrimoniales de una familia noble: los marqueses de Selva Nevada en la segunda mitad del siglo xviri y la primera del xix", en Gonzalbo Aizpuru y Rabell RomeRO, 1996, pp. 227-254.

Los nobles ante la muerte. Actitudes, ceremonias y memoria, 1750-1850, México, El Colegio de México, Instituto de Investigaciones Dr. José María Luis Mora, 2000. 
